\title{
Expression of free radicals by peritoneal cells of sheep during the early stages of Fasciola hepatica infection
}

\author{
Raúl Pérez-Caballero', Leandro Buffoni ${ }^{1 *}$, F. Javier Martínez-Moreno', Rafael Zafra', Verónica Molina-Hernández², \\ José Pérez ${ }^{2}$ and Álvaro Martínez-Moreno ${ }^{1}$
}

\begin{abstract}
Background: The majority of vaccination studies against infection with F. hepatica in a natural host have been conducted at the late stage of the infection when the host's immune response is already immunomodulated by the parasite towards a Th2 non-protective response. This study was aimed at analysing the dynamic of the cell populations present in peritoneal liquid and the production of free radicals by the peritoneal leukocytes in infected and vaccinated sheep with recombinant cathepsin L1 of $F$. hepatica ( $r F h C L 1)$ in early stages of the infection.

Methods: Forty-five sheep were divided into three groups: Group 1 remained as negative control $(n=5)$, Group 2 $(n=20)$ was challenged with F. hepatica and Group $3(n=20)$ was vaccinated with rFhCL1 and challenged with $F$. hepatica. After the slaughtering, peritoneal lavages were carried out at 1, 3, 9 and 18 days post-infection (dpi) to isolate peritoneal cell populations. Flow cytometry was conducted to assess levels of hydrogen peroxide $\left(\mathrm{H}_{2} \mathrm{O}_{2}\right)$ and nitric oxide (NO).

Results: There was a significant increase in the total number of leukocytes at 9 and $18 \mathrm{dpi}$ in infected and vaccinated groups. Production of $\mathrm{H}_{2} \mathrm{O}_{2}$ was significantly increased in peritoneal granulocytes in both infected and vaccinated groups. Production of nitric oxide showed a significant rise in the granulocytes and monocytes/macrophages in infected and vaccinated sheep. The NO production by granulocytes at 3 and 9 dpi was significantly higher in the vaccinated than in the infected animals.

Conclusions: Experimental infection induced an increase in the total number of leukocytes within the abdominal cavity at 9 and $18 \mathrm{dpi}$, being more noticeable in vaccinated animals. Production of $\mathrm{H}_{2} \mathrm{O}_{2}$ occurred mainly in granulocytes of vaccinated and infected animals. Production of $\mathrm{NO}$ was incremented in vaccinated and non-vaccinated animals in all peritoneal cells. Vaccinated animals produced significant higher level of $\mathrm{H}_{2} \mathrm{O}_{2}$ and $\mathrm{NO}$ than infected animals.
\end{abstract}

Keywords: Fasciola hepatica, Nitric oxide, ROS, Peritoneal cells, Vaccines, Sheep

\section{Background}

Fasciolosis, caused by Fasciola hepatica, is a globally distributed parasitic disease that mainly affects ruminant livestock and causes great impact in terms of economic losses to the agricultural industry [1, 2]. The World Health Organization (WHO) recognises it as a foodborne trematode infection and as an important zoonotic

\footnotetext{
* Correspondence: h12bupel@uco.es

${ }^{1}$ Animal Health Department (Parasitology and Parasitic Diseases), Faculty of Veterinary Medicine, University of Córdoba, Campus de Rabanales, Ctra. Madrid-Cádiz, km 396, 14014 Córdoba, Spain

Full list of author information is available at the end of the article
}

disease. Immature and mature forms of the parasite inhabits the liver of the host and produces a hepatitis which may alter the liver function [3].

There are few effective strategies to control the disease though it is widely accepted that the use of anthelmintics is the best means to control the infection. Specific drugs differ in their efficacy as some of them may not affect early immature stages of the parasite, hence triclabendazole (TCBZ) has become the drug of choice in many countries. A key drawback lies on the anthelmintic resistance to various drugs including TCBZ which has been globally reported [4-7]. Consequently, in the past

(c) The Author(s). 2018 Open Access This article is distributed under the terms of the Creative Commons Attribution 4.0 International License (http://creativecommons.org/licenses/by/4.0/), which permits unrestricted use, distribution, and 
two decades, many attempts have been conducted to develop a viable vaccine showing diverse results in cattle and sheep. The majority of the vaccination studies have been focussed on the late stage of the infection when the immune response of the host is known to be already immunomodulated by the parasite towards a nonprotective Th2 response and the inhibition of protective pro-inflammatory products $[8,9]$. Therefore, studies in infected and vaccinated animals during the early stage of infection, when the parasite is migrating and establishing in the liver may shed light on the initial immunological pathways of the disease.

Previous studies have shown that some parasites can trigger free radical production by leukocytes including superoxide radical, nitric oxide, and hydrogen peroxide $[10,11]$. In $F$. hepatica infections, resident peritoneal leukocytes such as macrophages might be involved in the killing of newly excysted juvenile liver flukes (NEJ). This may be accomplished by a parasite-specific antibody dependent mechanisms since most juvenile parasites are killed in the gut or the abdominal cavity, before reaching the liver [12]. In this way, some studies have shown an increase in the production of reactive oxygen species (ROS) produced by peritoneal leukocytes in rats infected with Fasciola hepatica [13, 14], which might be involved in the killing of migrating immature liver flukes during the early host-parasite interface. Moreover, free radical-induced cytotoxicity against NEJ of Fasciola sp. has been previously reported in infected sheep [15].

The aim of this work was to develop an in vivo study using flow cytometry in order to investigate the dynamic of the cell populations present in peritoneal liquid and the production of free radicals by leukocytes (macrophages and granulocytes) present in peritoneal liquid in infected animals (vaccinated and non-vaccinated) with recombinant cathepsin L1 of $F$. hepatica (rFhCL1) in early stages of the disease.

\section{Methods}

\section{Animals and experimental design}

Forty-five six-month-old male merino sheep obtained from a liver fluke-free farm were used for the experimental trial. Before beginning the study, animals were confirmed to be free of liver fluke infection by faecal analyses and ELISA for F. hepatica specific antibodies. Sheep were housed in covered pens and fed daily with hay and commercial pelleted ration.

Sheep were randomly divided into three groups: Group 1 consisted of 5 animals which were neither immunised nor experimentally challenged $(n=5)$, hence remained as negative control group, Group 2 consisted of 20 animals $(n=20)$ which were experimentally infected with $F$. hepatica (positive control group) and Group 3 consisted of 20 sheep which were immunised with
rFhCL1 and experimentally challenged with $F$. hepatica $(n=20)$. In addition, animals from Groups 2 and 3 were subdivided into smaller groups of five animals each according to slaughtering day: 1, 3, 9 and 18 days post-infection (dpi).

Animals from Group 3 received the vaccine twice by subcutaneous inoculation on weeks 0 and 4 of the trial. At week 8 of the experiment, animals from Groups 2 and 3 were orally challenged with one single dose of 150 metacercariae of $F$. hepatica (Ridgeway Research Ltd., St Briavels, UK) administered in gelatine capsules using a dosing gun. As previously mentioned, five animals from Groups 2 and 3 were euthanised by an intravenous injection of $\mathrm{T}^{\circ} 1^{\circ}$ (Intervet, Barcelona, Spain) at each time-point; animals from the negative control group (Group 1) were euthanised on the 12th week of the trial.

\section{Purification of recombinant $F$. hepatica cathepsin L1}

Recombinant $F$. hepatica cathepsin L1 (rFhCL1) was expressed in the yeast Pichia pastoris and purified as described elsewhere [16]. Yeast transformants were cultured in $250 \mathrm{ml}$ BMGY broth, buffered to $\mathrm{pH}$ 6.0, in 11 baffled flasks at $30{ }^{\circ} \mathrm{C}$ until an $\mathrm{OD}_{600}$ of 2-6 was reached. Cells were harvested by centrifugation at $2000 \times g$ for $5 \mathrm{~min}$ and protein expression was induced by resuspending the cells in $50 \mathrm{ml}$ BMMY broth, buffered at $\mathrm{pH} 6.0,7.0$ or 8.0 , containing $1 \%$ methanol. The cultures were grown at $30{ }^{\circ} \mathrm{C}$ with shaking at $225 \times \mathrm{rpm}$ for 3 days, and filter-sterilized methanol was added daily to maintain a final concentration of $1 \%$. Recombinant proteins were purified from the yeast medium by affinity chromatography using Ni-NTA-agarose (Qiagen, Montreal, Canada). Briefly, a column prepared with $1 \mathrm{ml}$ of resin was equilibrated by passing through $10 \mathrm{ml} 50 \mathrm{mM}$ sodium phosphate buffer ( $\mathrm{pH} 8.0)$ containing $300 \mathrm{mM}$ $\mathrm{NaCl}$ and $10 \mathrm{mM}$ imidazole. Ten millilitres of yeast media supernatant was mixed with $40 \mathrm{ml}$ of the same buffer and applied to the column. The column was washed with $15 \mathrm{ml}$ of $50 \mathrm{mM}$ sodium phosphate buffer (pH 8.0) containing $300 \mathrm{mM} \mathrm{NaCl}$ and $20 \mathrm{mM}$ imidazole, and bound protein was eluted using $50 \mathrm{mM}$ sodium phosphate buffer ( $\mathrm{pH} 7.0)$ containing $300 \mathrm{mM}$ $\mathrm{NaCl}$ and $250 \mathrm{mM}$ imidazole. Purified recombinant proteases were dialysed against phosphate buffered saline (PBS) and stored at $-20^{\circ} \mathrm{C}$. Before immunisation, electrophoresis in polyacrylamide gel was carried out to check protein purity.

\section{Vaccine preparation}

The recombinant protein cathepsin L1 of $F$. hepatica (rFhCL1) was diluted in ISA 70 Montanide adjuvant. Each immunisation dose was prepared as follows: $100 \mu \mathrm{g}$ of $\mathrm{rFhCL} 1$ was diluted in PBS containing $1 \mathrm{mg} / \mathrm{ml}$ of the adjuvant, reaching a final volume of $1 \mathrm{ml}$ per dose. 


\section{Liver pathology}

Necropsy was performed and the liver was removed and photographed on both visceral and diaphragmatic surface for gross evaluation. Liver tissue samples showing hepatic lesions were collected and fixed in 10\% neutral buffered formalin for $24 \mathrm{~h}$, then routinely processed and embedded in paraffin wax. Four-micron-thick tissue sections were stained with hematoxylin and eosin (H\&E) for histopathology. Gross hepatic lesions during the early stages of infection in challenged animals (Groups 2 and 3) were counted using the Image-Pro Plus 4.0 software (Media Cybernetics, Silver Spring, MD, USA).

\section{Antibody detection}

Blood samples were taken at weeks 0 and 6 of the trial and at 1, 3, 9 and 18 days post-infection (dpi), and plasma was collected to detect specific IgG1 and IgG2 antibodies against rFhCL1 by ELISA. Briefly, 96-well ELISA plates were coated with $5 \mu \mathrm{g} / \mathrm{ml}$ of $\mathrm{rFhCL} 1$ (100 $\mu \mathrm{l} /$ well) diluted in $0.05 \mathrm{M}$ carbonate-bicarbonate buffer $\mathrm{pH} 9.6$ and incubated at $37{ }^{\circ} \mathrm{C}$ overnight. After 5 washes with phosphate buffer saline (PBS) $0.05 \%$ Tween 20 , plates were blocked with $100 \mu \mathrm{l} /$ well of blocking buffer containing 1\% BSA diluted in PBS and incubated at $37{ }^{\circ} \mathrm{C}$ for $30 \mathrm{~min}$. To detect IgG1, wells were washed and $100 \mu \mathrm{l} /$ well of plasma diluted in blocking buffer was added and incubated at $37{ }^{\circ} \mathrm{C}$ for $30 \mathrm{~min}$. Triple serial dilutions were performed to determine endpoint titre. Similarly, IgG2 was detected by adding $100 \mu \mathrm{l} /$ well of plasma diluted at 1:25. After washing, $100 \mu \mathrm{l} /$ well of primary antibody diluted 1:5000 (mouse anti-bovine IgG1 and anti-bovine IgG2; 7500820-7500830 CediDiagnostics, Lelystad, The Netherlands), in blocking buffer was added and incubated at $37^{\circ} \mathrm{C}$ for $30 \mathrm{~min}$. After incubation, wells were washed and anti-mouse IgG-HRP (STAR13B, BIO-RAD - formerly AbD-Serotec-, Kidlington, UK) was added at $37{ }^{\circ} \mathrm{C}$ for $30 \mathrm{~min}$. Plates were washed and $100 \mu \mathrm{l} /$ well of tetramethylbenzidine (TMB; Sigma-Aldrich, Madrid, Spain) were added and incubated for $10 \mathrm{~min}$ at room temperature. The reaction was stopped by adding of $100 \mu \mathrm{l} /$ well of $1 \mathrm{M}$ sulphuric acid and optical density was measured at $450 \mathrm{~nm}$ using a microplate photometer (Multiskan ${ }^{\mathrm{TM}} \mathrm{FC}$, Thermo Fisher Scientific, Madrid, Spain). Results are shown as antibody titre $-\log _{10}$-for IgG1, and as optical density for IgG2.

\section{Isolation of peritoneal cell population}

To collect peritoneal cell population, abdominal lavage of each sheep was immediately conducted after the slaughtering as previously described [17]. Briefly, the ventral region of the abdomen was sheared, shaved and disinfected using $10 \%$ polyvinylpyrrolidone iodine (AGB, Madrid, Spain). A $2 \mathrm{~cm}$ incision was made in the skin over the midline and subcutaneous tissue was dissected.
The white line and peritoneum were sectioned with blunt scissors to avoid haemorrhage. A $40 \mathrm{~cm}$ long cannula connected to a syringe was inserted into the abdominal cavity and $40 \mathrm{ml}$ sterile DPBS containing 9500 UI of heparin (Eurotubo ${ }^{\circ}$, Madrid, Spain) (warmed at $37{ }^{\circ} \mathrm{C}$ ) was injected into the abdominal cavity. After softly massaging the abdominal cavity for $1 \mathrm{~min}, 40 \mathrm{ml}$ of peritoneal fluid were withdrawn. Peritoneal fluid was centrifuged at $1500 \times \mathrm{rpm}$ for $5 \mathrm{~min}$ and the supernatant was discarded. Cell pellets were resuspended again in DPBS and incubated for $15 \mathrm{~min}$ in an erythrolysis buffer $\left(0.15 \mathrm{M} \mathrm{NH}_{4} \mathrm{Cl}, 10 \mathrm{mM} \mathrm{KHCO}_{3}, 0.1 \mathrm{mM}\right.$ disodium EDTA, $\left.\mathrm{dH}_{2} \mathrm{O}\right)$. A second centrifugation step $(1500 \times \mathrm{rpm}$ for $5 \mathrm{~min}$ ) was performed to eliminate lysed erythrocyte membranes and the pellet was resuspended in $1 \mathrm{ml}$ of medium. After that, the concentration of peritoneal cells was quantified using the Trypan Blue exclusion technique. The final concentration was adjusted to $1 \times 10^{6}$ cells/ml for analysis by flow cytometry assay.

\section{Flow cytometry assay}

Flow cytometry acquisition was performed with a CyFlow Cube $6^{\circ}$ (Sysmex-Partec, Barcelona, Spain) cytometer. Leukocytes were identified by their characteristic appearance on a FSC-SSC dot plot and gated in order to exclude cellular debris. Ten thousand events were analysed for changes in fluorescence intensity (enzymatic activity) of macrophages and granulocytes. For oxidative metabolism, hydrogen peroxide $\left(\mathrm{H}_{2} \mathrm{O}_{2}\right)$ and nitric oxide (NO) production, filtered light at green was used (488 nm FL1 channel). The results were analysed using FCS Express 4.0 (DeNovo Software, Los Angeles, USA) and Flowing Software 2.0 (Centre for Biotechnology, Turku, Finland).

In order to measure intracellular $\mathrm{H}_{2} \mathrm{O}_{2}$, the cell-permeable dye DCFH-DA (Dichloro-dihydro-fluorescein diacetate) was used. The non-fluorescence reduced form is converted into the fluorescent form when is oxidised and, in this way, the fluorescence can be detected by flow cytometry. A $200 \mu \mathrm{l}$ sample of peritoneal cells were incubated in dark and $37{ }^{\circ} \mathrm{C}$ for $20 \mathrm{~min}$ with $1 \mathrm{ml}$ of DCFH-DA $10 \mu \mathrm{M}$. After incubation, samples were centrifuged at $1500 \times \mathrm{rpm}$ for $5 \mathrm{~min}$ and the supernatant was discarded. Two washes of PBS centrifuged at $1500 \times \mathrm{rpm}$ for $5 \mathrm{~min}$ were carried out and the pellets are resuspended in DPBS.

Intracellular $\mathrm{NO}$ was measured using the cell-permeable dye DAF-2DA (4,5-diaminofluorescein diacetate), because the non-fluorescent reduced form is converted into the fluorescent form when oxidised, thus allowing the detection by flow cytometry. In the same way, a $200 \mu \mathrm{l}$ sample of peritoneal cells was incubated in dark and $37{ }^{\circ} \mathrm{C}$ for $180 \mathrm{~min}$. From this point onwards the methodology was similar to that described for DCFH-DA. 


\section{Statistical analysis}

Statistical analysis was carried out with GraphPad Prism v.6.0 (GraphPad Software Inc., San Diego, CA, USA). The Kolmogorov-Smirnov test was applied to evaluate whether distributions were parametric. Comparison between pairs of groups was made using a two-tailed Mann-Whitney U-test for non-parametric distributions. $P<0.05$ was considered statistically significant.

\section{Results}

\section{Progression of infection: liver pathology and antibody} production

No hepatic changes were observed in the negative control animals (Group 1). In infected and vaccinated animals (Groups 2 and 3), gross and histopathological hepatic changes were absent at 1 and $3 \mathrm{dpi}$, though tortuous whitish tracts and haemorrhagic spots, which mainly occurred along the left hepatic lobe, were detected at 9 and 18 dpi. Further description of the gross hepatic lesions as well as the histopathological changes have been previously described in our recent study [18].

The levels of plasmatic specific anti-rFhCL1 IgG1 and IgG2 are presented in Fig. 1a, b. All vaccinated animals with the recombinant antigen developed an IgG1-IgG2 antibody response following immunisation. In vaccinated animals, a statistically significant production of IgG1 was detected after immunisation at each slaughtering time-point $(U=0, d f=8, P=0.0006$ for $6 \mathrm{wpv} ; U=0, d f=8$, $P=0.0097$ for 1,9 and $18 \mathrm{dpi}$ and $U=3, d f=8, P=0.0449$ for $3 \mathrm{dpi}$ ) and showing an increasing trend at the end of the trial (Fig. 1a). Production of IgG2 showed a similar pattern to that observed for IgG1 but was overall limited

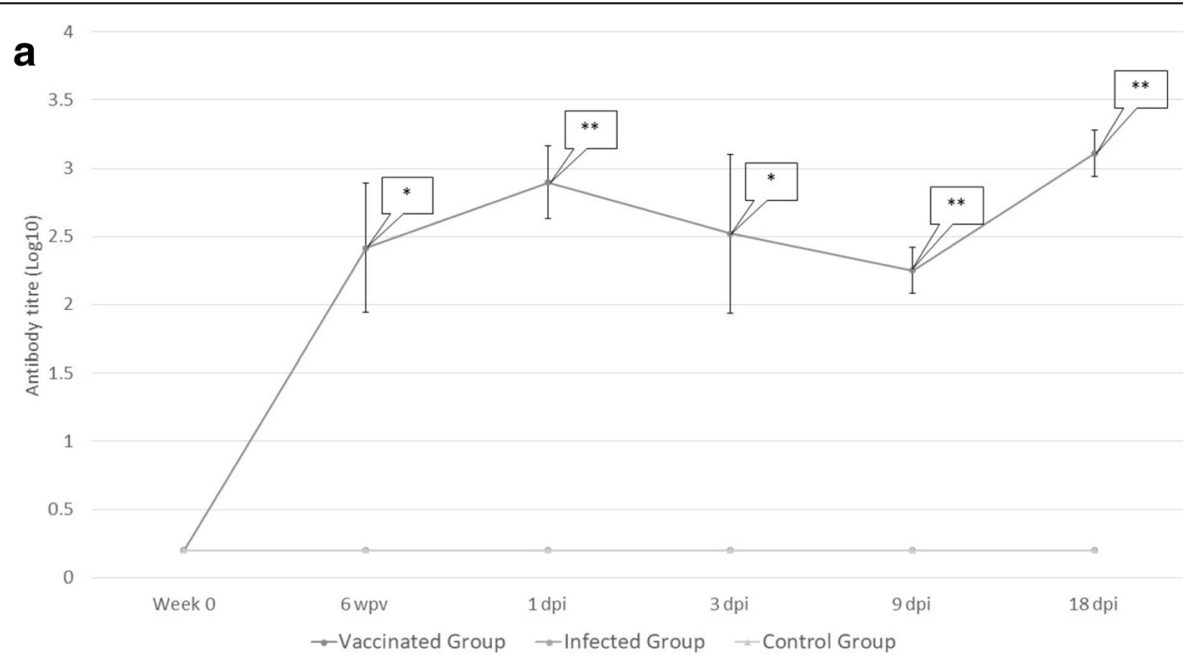

b

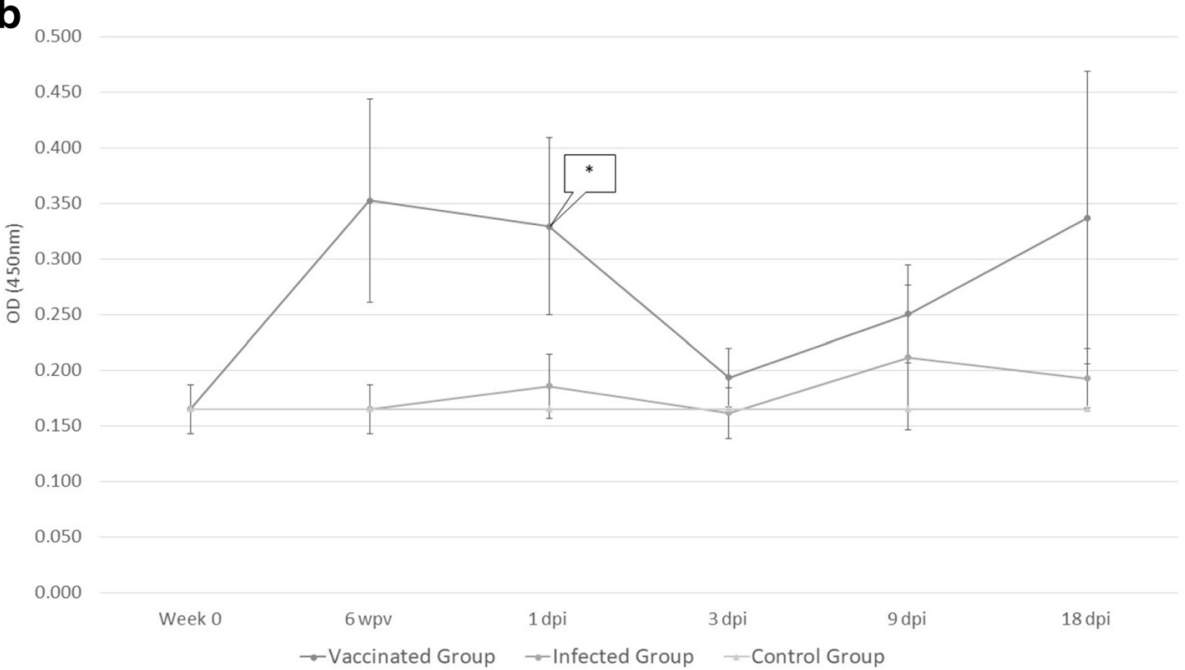

Fig. 1 Plasma levels of specific rFhCL1 lgG1 (a) and $\lg G 2$ (b). Each point represents mean values of antibody titre - $\log 10$ - (lgG1) and of optical density (IgG2) measured at $450 \mathrm{~nm}$. Bars at each point represents tandard error. Immunisation with rFhCL1 developed a significant rise in the level of $\lg G 1$ isotype; dynamics of $\lg \mathrm{G} 1$ in uninfected and infected sheep (Groups 1 and 2) shows a similar pattern, hence it is overlapped in the figure. Significant lgG2 production was detected only at 1 day post-infection (dpi) during the trial 
and only statistically significant after immunisation $(U=$ $2, d f=8, P=0.0062$; Fig. 1 b). No production of specific anti-rFhCL1 IgG1 and IgG2 was detected in the negative and positive control groups (Groups 1 and 2).

\section{Dynamics of peritoneal leukocytes during infection}

The total number of leukocytes population from peritoneal liquid was assessed by flow cytometry and expressed as $1 \times 10^{6}$ cells $/ \mathrm{ml}$. There was a significant increase in the number of leukocytes at 9 and $18 \mathrm{dpi}$, in both infected $(U=3, d f=8, P=0.0439$ and $U=0, d f=$ $8, P<0.0001$, respectively) and vaccinated $(U=0, d f=8$, $P=0.0009$ and $U=0, d f=8, P<0.0001$, respectively) groups in comparison with the negative control group (Fig. 2).

\section{Distribution of peritoneal leukocyte populations during infection}

Leukocyte populations were characterised by a side scatter/forward scatter profile as shown in Fig. 3a, b. Dynamics of cell populations through the infection is shown in Fig. 4a, b. The trend in all animals was an increase in the number of granulocytes and a decrease in both macrophages and lymphocytes throughout the infection.

Granulocytes were significantly increased in the infected group at $9 \mathrm{dpi}(U=0, d f=8, P=0.0129)$ and 18 dpi $(U=2, d f=8, P=0.0032)$. In the vaccinated group, a similar significant increment was detected at $9 \mathrm{dpi}(U$ $=3, d f=8, P=0.0481)$ and at $18 \mathrm{dpi}(U=0, d f=8, P=$ $0.0071)$. On the other hand, a significant decrease in the number of lymphocytes $(U=3, d f=8, P=0.0098)$ and macrophages $(U=6, d f=8, P=0.0291)$ was observed in the infected group at $18 \mathrm{dpi}$ compared with the negative control group (Group 1).

Lymphocytes and macrophages were significantly decreased in vaccinated animals $(U=0, d f=8, P=$ 0.0011 and $U=1, d f=8, P=0.0058$, respectively) and in infected group $(U=3, d f=8, P=0.0098$ and $U=6$, $d f=8, P=0.0291$, respectively) at $18 \mathrm{dpi}$ compared to negative control animals (Group 1). This decrease was also observed in the vaccinated animals at $3 \mathrm{dpi}$ for lymphocytes $(U=6, d f=8, P=0.0037)$ and at $9 \mathrm{dpi}$ for macrophages $(U=2, d f=8, P=0.0182)$, compared to the negative control group.

\section{Hydrogen peroxide production by peritoneal leukocyte populations during infection}

The results are shown in Fig. 5a, b. Production of $\mathrm{H}_{2} \mathrm{O}_{2}$ displayed a slightly different overall pattern in infected and vaccinated animals. During the initial stage of the infection, $\mathrm{H}_{2} \mathrm{O}_{2}$ production occurred mainly in the granulocyte cell type. In the infected group (Fig. 5a), the increase of $\mathrm{H}_{2} \mathrm{O}_{2}$ production by granulocytes was only observed at $18 \mathrm{dpi}(U=2, d f=8, P=0.0002)$. Nevertheless, a significant decrease was observed at $3 \mathrm{dpi}$ for monocytes/macrophages $(U=0, d f=8, P=0.0296)$.

In vaccinated animals (Fig. 5b) granulocytes showed a significant increase $(U=0, d f=8, P<0.0001)$ in $\mathrm{H}_{2} \mathrm{O}_{2}$ production at 9 and $18 \mathrm{dpi}$, whereas no significant variations were observed in the response of monocytes/ macrophages.

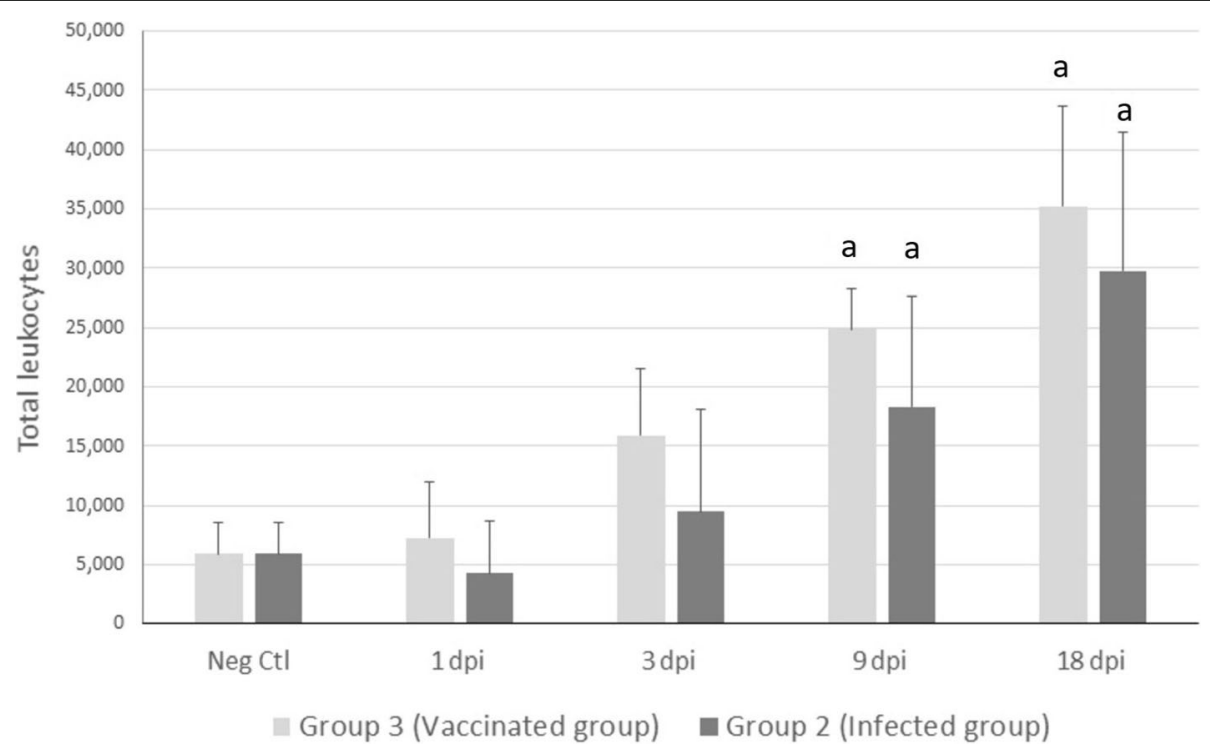

Fig. 2 Mean total number of leukocytes illustrating the effect of infection on peritoneal cell recruitment. Cell viability was assessed by trypan blue exclusion. "a" indicates significant variations between infected (Group 2, infected group), immunised (Group 3, vaccinated group) and control $($ Neg $\mathrm{Ctl})$ sheep $(P<0.05)$ at 4 slaughtering time-points: 1, 3, 9 and 18 days post-infection (dpi) 


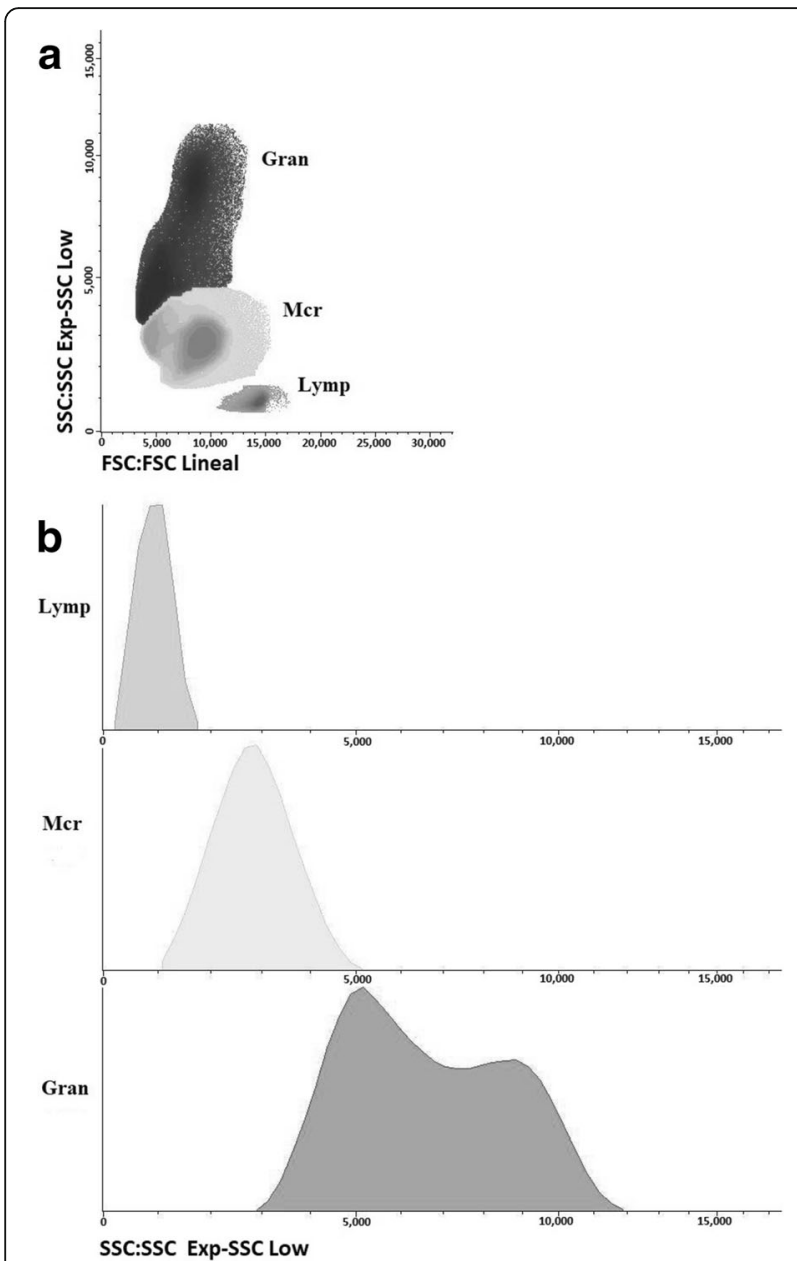

Fig. 3 Flow cytometry analysis of peritoneal cell population of sheep after peritoneal lavage characterised by a side scatter/forward scatter (SSC/FSC) profile. Distribution of major leukocyte populations on gated regions is represented by dot-plot (a) and histogram (b). Abbreviations: Lymp, lymphocytes; Mcr, macrophages; Gran, granulocytes

A statistically significant higher level of $\mathrm{H}_{2} \mathrm{O}_{2}$ production by granulocytes was observed in the vaccinated group than in the infected group at $9 \mathrm{dpi}(U=0, d f=8$, $P<0.0001)$.

\section{Nitric oxide production by peritoneal leukocyte populations during infection}

The dynamic of NO production is shown in Fig. 6a, b. In the infected animals (Fig. 6a) a significant rise in NO production was detected by granulocytes at $9 \mathrm{dpi}(U=0$, $d f=8, P=0.0432)$ and $18 \mathrm{dpi}(U=0, d f=8, P=$ $0.0076)$, and by monocytes/macrophages at $18 \mathrm{dpi}(U=$ $0, d f=8, P=0.0022$ ). In vaccinated sheep (Fig. 6b) the NO production by granulocytes was statistically significant increased at $3 \mathrm{dpi}(U=0, d f=8, P<0.0001), 9 \mathrm{dpi}$ $(U=0, d f=8, P=0.0026)$ and $18 \mathrm{dpi}(U=0, d f=8, P=$ $0.0133)$, whereas production by monocytes/macrophages was significantly increased only at $3 \mathrm{dpi}(U=0, d f=8$, $P<0.0001$ )

Production of NO by granulocytes was statistically significant higher at $3 \mathrm{dpi}(U=0, d f=8, P<0.0001)$ and 9 dpi $(U=3, d f=8, P=0.0476)$ in the vaccinated group than in the infected group.

\section{Discussion}

This study focuses on the production of free radicals by leukocyte populations in peritoneal fluid during the early stages of fasciolosis, being the first in vivo study carried out in sheep infected and uninfected with $F$. hepatica. We have compared the response in sheep vaccinated with $\mathrm{rFhCL} 1$ and non-vaccinated animals and we have confirmed the existence of a noticeable NO response, mainly by granulocytes, in both infected and vaccinated animals.

The peritoneal cavity is a critical location in the development of $F$. hepatica infection as it is the route of migration of $F$. hepatica NEJ from the intestine to the liver and the site where an early immunomodulatory effect of the parasite likely plays a critical role in determining the ultimate outcome of the infection [9]. It has been suggested that effector mechanisms of NEJ killing and consequent immune protection are dependent on the activity of peritoneal leukocytes, as described for $F$. hepatica in rats [19] and F. gigantica in Indonesian thin-tail sheep [15]. Both antibodies and free radicals (ROS and $\mathrm{NO})$ produced by leukocytes have been considered effective elements in those protective peritoneal responses [14]. However, ROS and NO produced as a strategy to kill parasites during $F$. hepatica infection have been also described as responsible for oxidative stress and hepatic damage in sheep [20], rats [21] and cattle [22].

In our experiment, peritoneal leukocyte populations in sheep increased immediately after infection, reaching significant levels at 9 and $18 \mathrm{dpi}$ in both infected and vaccinated groups, as previously described in rats experimentally challenged with $F$. hepatica [14]. From 9 dpi onwards, hepatic lesions could be detected, associated with the penetration of NEJ in the liver parenchyma. The cellular infiltration in hepatic lesions was mainly composed of eosinophils, macrophages and lymphocytes, whereas the peritoneal populations were mainly granulocytes, in increased proportions over the course of the infection. In our study, by using the flow cytometry assay, we could not discriminate the different cell population of granulocytes (neutrophils, eosinophils and basophils), but using immuno cytochemistry staining, we have determined that eosinophils occurred in more than $95 \%$ of total peritoneal granulocyte populations (data not shown) [23]. The predominance of granulocytes and more specifically of eosinophils in the peritoneal cell populations have been also observed in the early stage of infection in rats [11, 24], in 

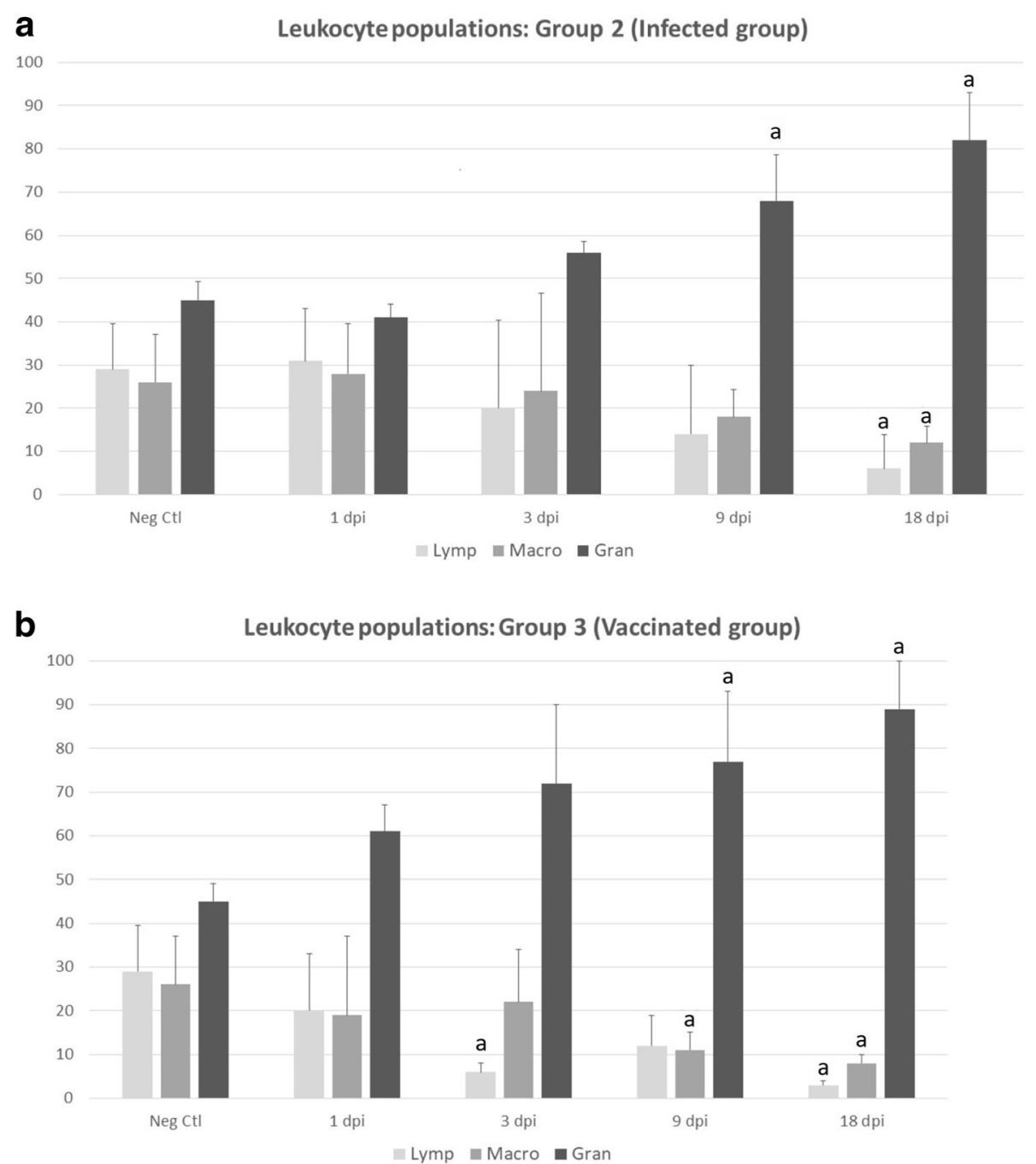

Fig. 4 Differential cell counts by flow cytometric analysis of peritoneal lavage leukocyte samples from uninfected (Neg Ctl, Group 1, a, b), infected (Group 2 , a) and vaccinated sheep (Group 3, b). Each identified cell subset is expressed as a percentage of the total number of leukocytes. Values represent the mean \pm SD. "a" indicates significant differences $(P<0.05)$ between groups. Abbreviations: Lymp, lymphocytes; Macro, macrophages; Gran, granulocytes

goats by immunohistochemical studies $[17,25]$ and in sheep by transcriptome analysis [26].

By means of the flow cytometry technique, we could assess the intracellular production of free radicals $\left(\mathrm{H}_{2} \mathrm{O}_{2}\right.$ and $\left.\mathrm{NO}\right)$ by peritoneal macrophages and granulocytes, although we could not identify the different oxidative response of neutrophils and eosinophils. The intracellular production of both $\mathrm{H}_{2} \mathrm{O}_{2}$ and NO by peritoneal leukocytes was stimulated during the early stages of infection, in the infected group and in the vaccinated group, as previously described in rats [14]. However, these authors found macrophages as the most significant cell type at the initial stage of the infection $(7 \mathrm{dpi})$ in contrast to our findings in sheep, in which granulocytes were proved to be more relevant cells at all time-points of the study.
We have also found that macrophages and particularly granulocytes from vaccinated animals showed a significantly higher production of free radicals, mainly at 9 and $18 \mathrm{dpi}$. This is consistent with our previous work where a partial protective response was described in experimental trials with $\mathrm{rFhCL1}$, that could be related to eosinophils and free radical (NO) production in the early stage of infection $[17,18]$.

The role of $\mathrm{H}_{2} \mathrm{O}_{2}$ in $F$. hepatica infection remains unclear. Transcriptome studies in mice revealed production of ROS as one the most significant pathways undergoing changes during immunoprotection [27] but it has also been related to oxidative stress and pathology in chronic infection in sheep [20]. Moreover, different in vitro studies indicate that $F$. hepatica NEJ possess a unique ability to resist killing by reactive oxygen species released by 

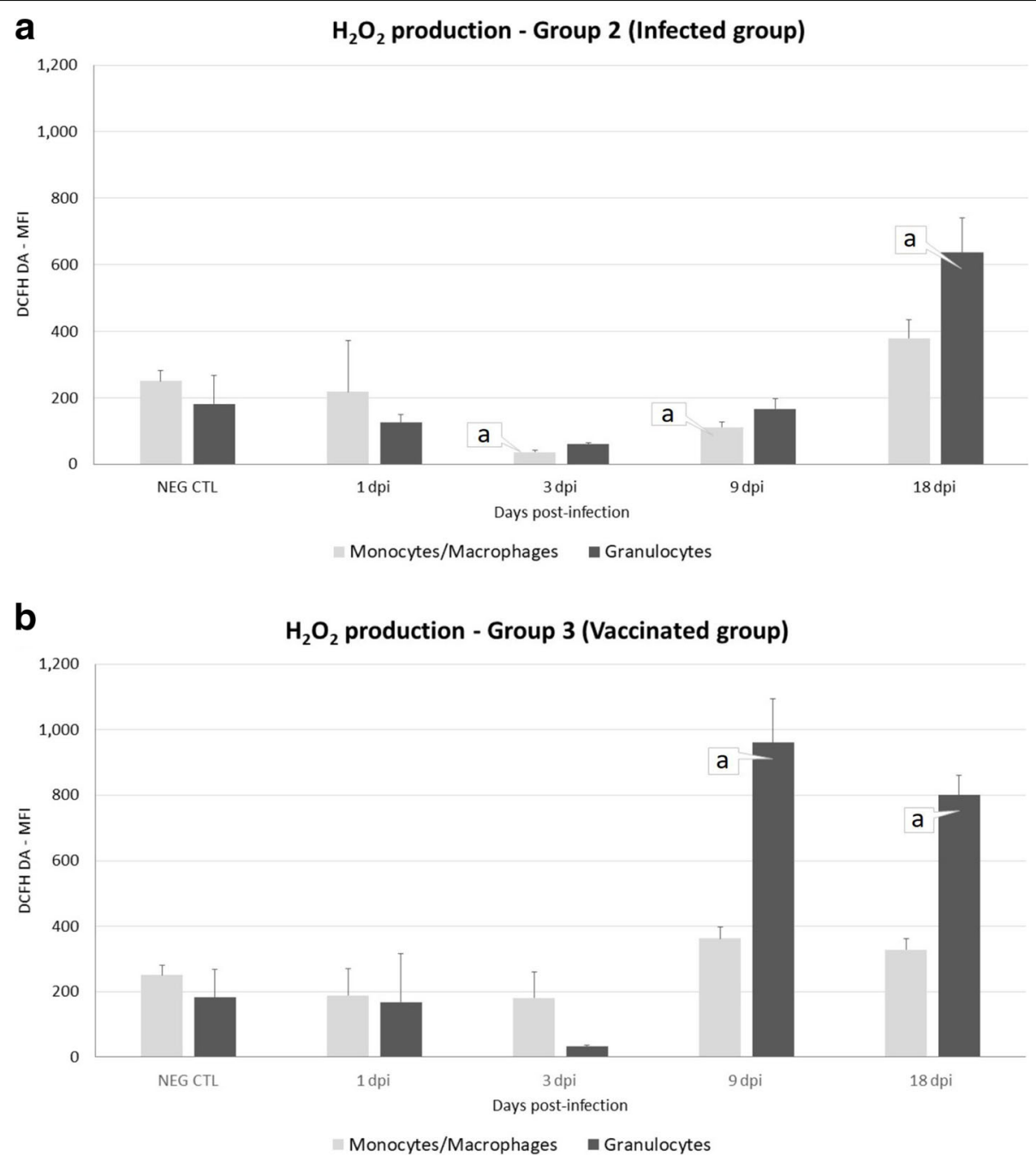

Fig. 5 Mean fluorescence intensity of $\mathrm{H}_{2} \mathrm{O}_{2}$ production (DCFH DA) in the peritoneal fluid of uninfected sheep (Neg. Ctl, Group 1, a, b), infected (Group 2, a) and vaccinated sheep (Group 3, b). Values represent the mean \pm standard deviation, SD. "a" indicates significant differences $(P<0.05)$ between groups

sheep innate immune effector cells, which may involve the high expression of antioxidant enzymes such as superoxide dismutase, glutathione S-transferase (GST) or peroxiredoxin [28-31].

In our study, both macrophages and granulocytes were involved in the increase of NO production occurring between 3 and $18 \mathrm{dpi}$. Previous studies in rats have highlighted the involvement and complementary role of these two cell populations in the peritoneal stage of the infection [11, 14, 31]. In fact, Piedrafita et al. [15] described an antibody-dependent cell-mediated killing of NEJ involving both macrophages and eosinophils NO production in the resistance of ITT sheep to F. gigantica. Our previous vaccination study suggested that inducible nitric oxide synthase (iNOS) expression and subsequent NO production could be important for an effective response against the early migrating liver fluke [17]. Although the early production of $\mathrm{NO}$ we have detected in that study seemed to have little effect on the development of the infection and in the final fluke burden at the end of the experiment [18]. Consistent protective responses in sheep has not been achieved and the precise effective mechanisms of protection has not been yet elucidated [9]. It has been hypothesised that NO and iNOS might play an important role in F. hepatica pathogenesis, possibly as an effective mechanism for killing migrating NEJ, as it has been previously shown to occur in resistant rats [31] or maybe as an expression of M1 macrophages activation which are known to be related to the development of Th1 responses required for protection [18, 32, 33]. Recent transcriptomic studies have revealed that modifications in the NO signalling pathway may be a necessary condition for immunoprotection in mice [27] or, on the contrary, downregulation of iNOS might be a paramount factor during the non-protective response occurring in sheep [34]. In our study, we have 

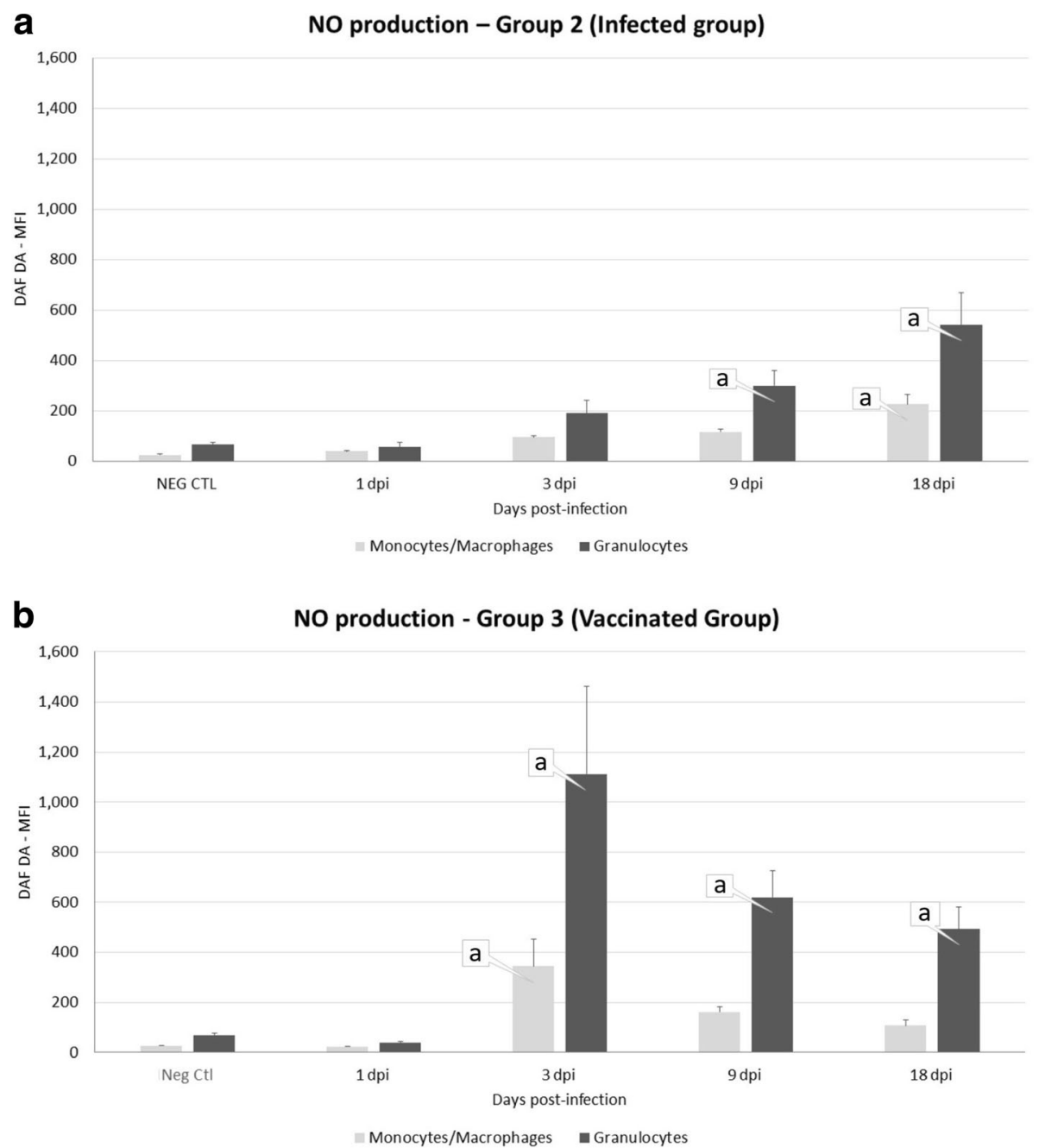

Fig. 6 Mean fluorescence intensity of NO production (DAF DA) in the peritoneal fluid of sheep uninfected (Neg Ctl, Group 1, a, b), infected (Group $2, \mathbf{a})$ and vaccinated sheep (Group 3, b). Values represent the mean \pm standard deviation, SD. "a" indicates significant differences $(P<0.05)$ between groups

not detected an inhibition in NO production in the early phase of infection. In another study, we found a low level of variation in iNOS expression in peritoneal macrophages by immunocytochemistry [35]. Those differences suggest that iNOS gene, protein expression and NO production in the initial stages of the infection may differ, with the protein probably remaining active for a longer time than the gene.

In conclusion, we have observed a clear leukocyte response in the peritoneal cavity of the sheep in the early stage of $F$. hepatica infection. The leukocyte populations, mainly granulocytes, exhibited a metabolic response with intracellular production of both $\mathrm{H}_{2} \mathrm{O}_{2}$ and NO. The effect of those free radicals on the NEJ and migrating juveniles it is still unclear, since NEJ and migrating juveniles appear to be unaffected by those molecules as they reached the liver and evolved to mature stages. Further studies are needed to provide a broader insight on the biomolecular mechanisms involved in the evasion of the immune response of this parasite in the early stages of infection.

\section{Conclusions}

Experimental infection induced an increase in the total number of leukocytes within the abdominal cavity at 9 and 18 dpi which was characterised by an increase in the number of granulocytes and a decrease of both macrophages and lymphocytes. Production of both $\mathrm{H}_{2} \mathrm{O}_{2}$ and $\mathrm{NO}$ by peritoneal cells was increased in vaccinated and non-vaccinated animals. Granulocytes were mainly involved in $\mathrm{H}_{2} \mathrm{O}_{2}$ production, whereas granulocytes and macrophages were predominant in NO production. Vaccinated animals produced a significantly higher level of $\mathrm{H}_{2} \mathrm{O}_{2}$ and $\mathrm{NO}$ than infected animals. 


\section{Abbreviations}

dpi: days post-infection; GST: glutathione S-transferase; $\mathrm{H}_{2} \mathrm{O}_{2}$ : hydrogen peroxide; iNOS: inducible nitric oxide synthase; NEJ: newly excysted juveniles; NO: nitric oxide; rFhCL1: recombinant cathepsin L1 of Fasciola hepatica; ROS: reactive oxygen species; TCBZ: triclabendazole; wpv: weeks postvaccination

\section{Acknowledgements}

The authors are grateful to Professor J. P. Dalton (Queen's University Belfast, Northern Ireland, UK) for providing the rFhCL1.

\section{Funding}

This study was funded by the European Union Grant H2020-635408-PARAGONE and by National Grant AGL2015-67023-C2-1-R. Raúl Pérez Caballero was supported by a FPU grant of the Spanish Ministry of Education, Culture and Sport. Funding bodies were neither involved in the design of the study nor in analysis and interpretation of the data.

\section{Availability of data and materials}

Data supporting the conclusions of this study are included within the article. Raw data are available from the corresponding author upon request.

\section{Authors' contributions}

RPC, LB, FJMM, RZ, VHM, JP and AMM conceived and designed the study. RPC, LB and RZ collected and analysed the samples. RPC, LB and AMM performed the statistical analysis. All authors read and approved the final manuscript.

\section{Ethics approval and consent to participate}

This experiment was performed in accordance with the University of Cordoba Bioethics Committee (no. 7119) and European (86/609/CEE) and Spanish Directives (RD 223/1988)

\section{Consent for publication}

Not applicable.

\section{Competing interests}

The authors declare that they have no competing interests.

\section{Publisher's Note}

Springer Nature remains neutral with regard to jurisdictional claims in published maps and institutional affiliations.

\section{Author details}

${ }^{1}$ Animal Health Department (Parasitology and Parasitic Diseases), Faculty of Veterinary Medicine, University of Córdoba, Campus de Rabanales, Ctra. Madrid-Cádiz, km 396, 14014 Córdoba, Spain. ${ }^{2}$ Anatomy and Comparative Pathology Department, Faculty of Veterinary Medicine, University of Córdoba, Campus de Rabanales, Ctra. Madrid-Cádiz, km 396, 14014 Córdoba, Spain.

\section{Received: 8 June 2018 Accepted: 21 August 2018}

\section{Published online: 06 September 2018}

\section{References}

1. Spithill TW, Smooker PT, Sexton JL, Bozas E, Morrison CA, Creany J, et al. Development of vaccines against Fasciola hepatica. In: Dalton JP, editor. Fasciolosis. Wallingford, UK: CABI Publishing; 1999. p. 377-410.

2. Piedrafita D, Spithill TW, Smith RE, Raadsma HW. Improving animal and human health through understanding liver fluke immunology. Parasite Immunol. 2010:32:572-81.

3. Behm CA, Sangster NC. Pathology, pathophysiology and clinical aspects. In: Dalton JP, editor. Fasciolosis. Wallingford, UK: CABI Publishing; 1999. p. $185-224$

4. Olaechea F, Lovera V, Larroza M, Raffo F, Cabrera R. Resistance of Fasciola hepatica against triclabendazole in cattle in Patagonia (Argentina). Vet Parasitol. 2011;178:364-6

5. Brockwell YM, Elliott TP, Anderson GR, Stanton R, Spithill TW, Sangster NC. Confirmation of Fasciola hepatica resistant to triclabendazole in naturally infected Australian beef and dairy cattle. Int J Parasitol Drugs Drug Resist. 2013:4:48-54.
6. Novobilský A, Höglund J. First report of closantel treatment failure against Fasciola hepatica in cattle. Int J Parasitol Drugs Drug Resist. 2015;5:172-7.

7. Venturina VM, Alejandro MA, Baltazar CP, Abes NS, Mingala CN. Evidence of Fasciola spp. resistance to albendazole, triclabendazole and bromofenofos in water buffaloes (Bubalus bubalis). Ann Parasitol. 2015;61:283-9.

8. Dalton JP, Robinson MW, Mulcahy G, O'Neill SM, Donelly S. Immunomodulatory molecules of Fasciola hepatica: candidates for both vaccine and immunotherapeutic development. Vet Parasitol. 2013;195:272-5

9. Molina-Hernández V, Mulcahy G, Pérez J, Martínez-Moreno Á, Donnelly S, O'Neill SM, et al. Fasciola hepatica vaccine: we may not be there yet but we're on the right road. Vet Parasitol. 2015;208:101-11.

10. Wandurska-Nowak E, Wisniewska J. Release of nitric oxide during experimental trichinellosis in mice. Parasitol Res. 2002;88:708-11.

11. Sibille $\mathrm{P}$, Tliba $\mathrm{O}$, Boulard $\mathrm{CH}$. Early and transient cytotoxic response of peritoneal cells from Fasciola hepatica-infected rats. Vet Res. 2004;35:576-84.

12. Armour J, Dargie JD. Immunity to Fasciola hepatica in rat. Successful transfer of immunity by lymphoid-cells and by serum. Exp Parasitol. 1974;35:381-8.

13. Smith NC, Ovingston KS, Boray JC. Fasciola hepatica free radical generation by peritoneal leukocytes in challenged rodents. Int J Parasitol. 1992;22:281-6.

14. Jedlina L, Kozak-Ljunggren M, Wedrychowicz H. In vivo studies of the early, peritoneal, cellular and free radical response in rats infected with Fasciola hepatica by flow cytometric analysis. Exp Parasitol. 2011;128:291-7.

15. Piedrafita D, Estuningsih E, Pleasance J, Prowse R, Raadsma HW, Meeusen ENT, et al. Peritoneal lavage cells of Indonesian thin-tail sheep mediate antibody-dependent superoxide radical cytotoxicity in vitro against newly excysted juvenile Fasciola gigantica but not juvenile Fasciola hepatica. Infect Immun. 2007;75:1954-63.

16. Collins PR, Stack CN, O'Neill SM, Doyle S, Ryan T, et al. Cathepsin L1, the major protease involved in liver fluke (Fasciola hepatica) virulence: propeptide cleavage sites and autoactivation of the zymogen secreted from gastrodermal cells. J Biol Chem. 2004;279:17038-46.

17. Zafra R, Perez-Ecija RA, Buffoni L, Pacheco IL, Martinez-Moreno A, LaCourse EJ, et al. Early hepatic and peritoneal changes and immune response in goats vaccinated with a recombinant glutathione transferase sigma class and challenged with Fasciola hepatica. Res Vet Sci. 2013;94:602-9.

18. Pacheco IL, Abril N, Morales-Prieto N, Bautista MJ, Zafra R, Escamilla A, et al. Th1/Th2 balance in the liver and hepatic lymph nodes of vaccinated and unvaccinated sheep during acute stages of infection with Fasciola hepatica. Vet Parasitol. 2017;238:61-5.

19. Kesik M, Jedlina-Panasiuk L, Kozak-Cieszczyk M, Płucienniczak A, Wedrychowicz $\mathrm{H}$. Enteral vaccination of rats against Fasciola hepatica using recombinant cysteine proteinase (cathepsin L1). Vaccine. 2007:25:3619-28.

20. Saleh MA. Circulating oxidative stress status in desert sheep naturally infected with Fasciola hepatica. Vet Parasitol. 2008;154:262-9.

21. Bottari NB, Mendes RE, Lucca NJ, Schwertz Cl, Henker LC, Olsson DC, et al. Oxidative stress associated with pathological lesions in the liver of rats experimentally infected by Fasciola hepatica. Exp Parasitol. 2015;159:24-8.

22. Mendes EA, Mendes TA, dos Santos SL, Menezes-Souza D, Bartholomeu DC, Martins IVF, et al. Expression of IL-4, IL-10 and IFN-gamma in the liver tissue of cattle that are naturally infected with Fasciola hepatica. Vet Parasitol. 2013:195:177-82.

23. Ruiz-Campillo MT, Hernandez VM, Escamilla A, Perez J, Martinez-Moreno A, Donnelly $S$, et al. Immune signatures of pathogenesis in the peritoneal compartment during early infection of sheep with Fasciola hepatica. Sci Rep. 2017:7:2782

24. Van Millingen FJ, Cornelissen JBWJ, Hendriks IM, Gaasenbeek CPH, Bokhout BA. Protection to Fasciola hepatica in the gut mucosa of immune rats is associated with infiltrates of eosinophils, IgG1 and lgG2a antibodies around the parasites. Parasite Immunol. 1998;20:285-92.

25. Zafra R, Perez-Ecija RA, Buffoni L, Moreno P, Bautista MJ, Martinez-Moreno A et al. Early and late peritoneal and hepatic changes in goats immunized with recombinant cathepsin L1 and infected with Fasciola hepatica. J Comp Pathol. 2013;148:373-84

26. Alvarez Rojas CA, Ansell BR, Hall RS, Gasser RB, Young ND, Jex AR, et al. Transcriptional analysis identifies key genes involved in metabolism, fibrosis/ tissue repair and the immune response against Fasciola hepatica in sheep liver. Parasit Vectors. 2015;8:124

27. Rojas-Caraballo J, López-Abán J, Moreno-Pérez DA, Vicente B, FernándezSoto $P$, del Olmo E, et al. Transcriptome profiling of gene expression during 
immunisation trial against Fasciola hepatica: identification of genes and pathways involved in conferring immunoprotection in a murine model. BMC Infect Dis. 2017;17:94.

28. Piedrafita D, Spithill TW, Dalton JP, Brindley PJ, Sandeman MR, Wood PR, et al. Juvenile Fasciola hepatica are resistant to killing in vitro by free radicals compared with larvae of Schistosoma mansoni. Parasite Immunol. 2000;22: 287-95.

29. Donnelly S, O'Neill SM, Sekiya M, Mulcahy G, Dalton JP. Thioredoxin peroxidase secreted by Fasciola hepatica induces the alternative activation of macrophages. Infect Immun. 2005;73:166-73.

30. Donnelly S, Stack CM, O'Neill SM, Sayed AA, Williams DL, Dalton JP. Helminth 2-Cys peroxiredoxin drives Th2 responses through a mechanism involving alternatively activated macrophages. FASEB J. 2008;22:4022-32.

31. Piedrafita D, Parsons JC, Sandeman RM, Wood PR, Estuningsih SE, Partoutomo S, et al. Antibody-dependent cell-mediated cytotoxicity to newly excysted juvenile Fasciola hepatica in vitro is mediated by reactive nitrogen intermediates. Parasite Immunol. 2001;23:473-82.

32. Flynn RJ, Irwin JA, Olivier M, Sekiya M, Dalton JP, Mulcahy G. Alternative activation of ruminant macrophages by Fasciola hepatica. Vet Immunol Immunopathol. 2007;120:31-40.

33. Garza-Cuartero L, O'Sullivan J, Blanco A, McNair J, Welsh M, Flynn RJ, et al. Fasciola hepatica infection reduces Mycobacterium bovis burden and mycobacterial uptake and suppresses the pro-inflammatory response. Parasite Immunol. 2016:38:387-402.

34. Fu Y, Chryssafidis AL, Browne JA, O'Sullivan J, McGettigan PA, Mulcahy G. Transcriptomic Study on Ovine Immune Responses to Fasciola hepatica Infection. PLoS Negl Trop Dis. 2016;10:e0005015.

35. Ruiz-Campillo MT, Molina-Hernández V, Pérez J, Pacheco IL, Pérez R, Escamilla A. Study of peritoneal macrophage immunophenotype in sheep experimentally infected with Fasciola hepatica. Vet Parasitol. 2018;257:34-9.

Ready to submit your research? Choose BMC and benefit from:

- fast, convenient online submission

- thorough peer review by experienced researchers in your field

- rapid publication on acceptance

- support for research data, including large and complex data types

- gold Open Access which fosters wider collaboration and increased citations

- maximum visibility for your research: over $100 \mathrm{M}$ website views per year

At $\mathrm{BMC}$, research is always in progress.

Learn more biomedcentral.com/submissions 